\title{
Tradisie-historiese probleme rondom 'versoening' by Paulus
}

\author{
Cilliers Breytenbach
}

\section{Abstract}

Tradicio-historical problems on 'reconciliation' in Paul

In a short Afrikaans essay Breytenbach summerizes the findings of a recent investigation on the background of Paul's use of katallagē (cf Cilliers Breytenbach, KATALLAGE: Eine Studie zur paulinischen Soteriologie, to appear in WMANT Neukirchener Verlag). The Pauline usage has its roots in the diplomatic language of the Hellenistic era. Paul the legatus or presbeús (2 Cor 5:20) uses this concept to explain his function of mediating God's message of reconciliation to man (2 Cor 5:18f). True to his general presuppositions, Paul re-interprets the profane concept of katallage by stating that the death of Christ 'for us' (2 Cor 5:14) made reconciliation possible (2 Cor 5:19; Rm 5:9f).

\section{PROBLEEM EEN: VERSOENING (KATALLAGÉ) EN VERSOEN (HILÁSKESTHAI)}

Wanneer 'n mens oor die Pauliniese versoeningstekste praat, moet 'n mens duidelikheid daaroor hê watter tekste hier ter sprake is. In Afrikaans praat ons van 'versoen' en beroep ons daarvoor op twee Griekse woorde katallássein en hiláskesthai. Hierdie gebruik, wat vas ingeburger is in die Afrikaanse en Nederlandse teologiese tradisie, gaan via die Statenvertaling op Martin Luther terug. Die Wittenbergse reformator het, heeltemal korrek vir die Duits van die dag, katallássein en hiláskesthai met versünen vertaal. Wat Luther ook gedoen het, is om kippẹ en kōper in die Ou Testament met versünen en afgeleide vorme te vertaal. Die Nederlands, en dus ook Afrikaans, volg hierdie gebruik en vertaal tot vandag toe enkelvoudig met 'versoen'. In die moderne Duits het die werkwoord versü $(h)$ nen in onbruik geraak en word versöhnen en sühnen beide gebruik. Alhoewel Duitse Nuwe-Testamentici daartoe neig om hiláskesthai en afgeleide vorme met sühnen en Sühne te vertaal, terwyl hulle katallássein en afgeleide vorme met versöhnen of dan Versöhnung vertaal, gebruik Duitse Ou-Testamentici beide woorde as stilistiese variante.

* Referaat gelewer by die NTWSA Paulus-subgroep, Potchefstroomse Universiteit vir CHO op 10 April 1986. Die artikel word binnekort deur ' $n$ tweede studie in die HTS opgevolg. 
Wanneer 'n mens na die gebruik by Engelse teoloë kyk, dan word die saak skielik problematies. Terwyl hulle gewoonlik expiate, atone en atonement as Engelse ekwivalente vir hilaskesthai en afgeleide vorme gebruik, word reconciliation in verband met katallássein en katallagè gebruik.

Die vraag wat nou opkom is die volgende: Staan hiláskesthai en katallássein in noue sinsverwantskap (hiponimie of selfs sinonimie) tot mekaar, soos wat die Duits-Nederlands-Afrikaanse tradisie suggereer, of het ons hier met verskillende semantiese velde te doen, soos wat die Latynse en Engelse vertalingstradisie suggereer?

In 'n monografie* wat eersdaags gepubliseer word, het ek aangetoon dat katallássein en hiláskesthai nie as hiponieme beskou kan word nie. Die gebruik van beide woorde in die corpus hellenisticum bewys dat hulle tot twee verskillende betekenisvelde hoort en ook nie in referensie-moontlikheid oorvleuel nie. Die Germaanse tradisie om beide met 'versoen' te verhaal, skep oneindige verwarring. Ek stel voor dat ons na alternatiewe begin soek (vgl ook Fryer 1984).

\section{PROBLEEM TWEE: DIE PAULINIESE KATALLAGË en die OU- TESTAMENTIESE VERSOENINGSTERMINOLOGIE}

Dit is weliswaar so dat hiláskesthai en katallássein in die koinē in geen hiponieme relasie tot mekaar staan nie, maar wat is die posisie met die LXX? Wanneer ' $n$ mens na die $L X X$ se verskeie vertalings van kippẹr en kōper kyk, is dit onbetwisbaar dat dia- of katallássein nie as vertalingsekwivalent gebruik word nie. Trouens dia- of katallássein en afgeleide vorme kom selde in die sin van 'versoen' in die LXX voor: diallássein in Rigters 19:31, 1 Esdras 4:31 en 1 Bas 29:46; diallage $\bar{e}$ in Sophia Siraks 22:22; $27: 21$ en katallássein in 2 Makk 1:5; 33; 8:29 met katallage in 2 Makk 5:20. In die gevalle waar 'n mens wel die Hebreeuse teks kan vergelyk, naamlik Rigters 19:31 en 1 Samuel 29:46, is dit duidelik dat hier geen verband met kippẹr en kōpẹ en afleidings bestaan nie. In Rigters 19:31 word šōb en 1 Samuel 29:34 word rāşā gebruik.

Soos algemeen bekend is, word kippęr en afleidings hoofsaaklik met (ex-)iláskesthai en afgeleide vorme vertaal. Hierdie gebruik van (ex-)ilás$k e s t h a i$ is eie aan veral die Levitikusvertaling in die LXX. 'n Noukeurige ondersoek van hierdie tekste waar (ex-)iláskesthai gebruik word om

- Vgl Cilliers Breytenbach, KATALLAGẼ: Eine Studie zur paulinischen Soteriologie, Neukirchener Verlag. (WMANT.) Alle standpunte in hierdie referaat word in die boek, wat in druk is, breedvoerig bespreek. 
vorme van kipper te vertaal, lei tot die konklusie dat (ex-)iláskesthai in die LXX nie op so ' $n$ wyse gebruik word dat dit as ' $n$ hiponiem van katallássein kan geld of die tradisie-historiese agtergrond van Paulus se gebruik van katallássein kan bied nie.

Hierdie bevinding verklaar ' $n$ baie interessante verskynsel wat elke noukeurige leser van die Pauliniese tekste opval. Alhoewel die Afrikaanse en Nederlandse Bybelvertalings hiláskesthai en katallássein beide met 'versoen' vertaal, kom hierdie twee woorde of hulle afleidings nêrens in die Nuwe Testament in dieselfde konteks voor nie. Trouens die enigste geskrif wat beide woordgroepe gebruik, is die Romeinebrief. In Romeine 3:25 gebruik Paulus die gesubstansiveerde adjektief hilastērion en in Romeine 5:10v en 11:15 word katallássein en katallagē gebruik. Voordat 'n mens egter op die klank van die Afrikaanse of Nederlandse vertalings af Romeine 3:25 en 5:10v oor een boeg gooi, is dit belangrik om die hoofteks van die Pauliniese versoeningsleer, naamlik 2 Korintiërs 5:18-21, onder die loep te neem.

As bevinding van hierdie gedeelte kan ons egter sê: Nòg die MT se gebruik van $k p r$ en afgeleide vorme, nòg die LXX se gebruik van (ex-) iláskesthai as vertalingsekwivalent kan $k p r$, verklaar die herkoms van die Pauliniese versoeningsterminologie.

\section{PROBLEEM DRIE: PAULUS EN DIE GEBRUIK VAN KATALLÁSSEIN BY ANDER GRIEKSSPREKENDE JODE}

Die vraag wat nou opkom, is of die gebruik van katallássein of diallássein in die LXX nie die gebruik by Paulus sou verklaar nie. Dit is natuurlik net sinnig om die LXX in te sleep as Paulus en die LXX 'n spesifieke gebruik van katallássein vertoon wat van die algemene profane gebruik in die koinē afwyk. In 1 Korintiërs 7:11 gebruik Paulus katallássein om na die versoening tussen man en vrou te verwys. Hierdie gebruik sluit - soos die diallássein in LXX Rigters 19:3, 1 Esdras $4: 31$ - by die algemene profane gebruik aan en het dus geen besondere verklaring nodig nie. Dieselfde geld vir die gebruik in 1 Bas 29:46; Sophia Siraks 22:22; 27:21. Hier gaan dit op menslike vlak om die versoening tussen twee twistende persone, 'n gebruik wat in die koine dikwels opduik.

Die punt is egter: By Paulus en in die 2de Makkabeërboek gaan dit om versoening tussen God en mens. Is hierdie ook ' $n$ algemene gebruik in die koine $\bar{e}$. Die antwoord is nee. Die woordgroep dia- en katallássein word slegs by Paulus, in die 2de Makkabeërboek, by Philo van Alexan- 
drië en by Flavius Josefus gebruik om na die verhouding tussen God en mens te verwys. Ons het géén profane teks uit die tyd na Alexander die Grote wat bewys dat die versoeningsterminologie in 'n religieuse sin gebruik is nie. Trouens, ons het tot op hede net twee bewysplase buite die Griekssprekende Jodedom dat die terminologie hoegenaamd in 'n religieuse verband gebruik is: uit die Aiax van Sophokles (Aj 744 \pm 450 v C) en die Symposium van Plato (Symp 1933 - voor 348 v C). Hierdie twee tekste is te vroeg en te $\mathrm{min}$ om te kan verklaar waarom Paulus die terminologie gebruik om die verhouding tussen God en mens uit te druk.

Geen mens praat en skryf in 'n lugleegte nie. Waar kom Paulus se gebruik van katallássein vandaan? Het hy dit werklik vanuit die Griekssprekende Jodedom oorgeneem? Wanneer 'n mens die religieuse gebruik van katallássein in 2 Makk 1:5; 7:33; 8:29; Jos Ant 6:143; Philo Praem 166 en fragment II 6, 70; van katallage in 2 Makk 5:20; van dialláttein in Jos Ant 6:151; 7:153.295; van diallaktês in Philo VitMos 2:166 en van eudiallaktós in Jos BJ 5:415 met die Pauliniese gebruik vergelyk, word die volgende duidelik:

Eerstens is daar geen uniforme gebruik van die terminologie nie. Ons kan dus geensins van 'n spesifieke gebruik binne die Griekssprekende Jodedom praat nie.

Wat wel waar is, is dat Philo en Josefus soos Paulus die versoeningsterminologie in ' $n$ wyer sin op die verhouding tussen God en mens aanwend.

Tweedens verskil die manier waarop Josefus en die 2de Makkabeërboek die verhouding tussen God en mens beskryf, ingrypend van dié by Paulus. By Paulus gaan dit om God se daad. God handel en versoen die mens met homself. Dit beteken dat God die mens in 'n nuwe relasie tot homself bring en nie dat God sy gesindheid teenoor die mens verander het nie. By Josefus en in die 2 de Makkabeërboek gaan dit om ' $n$ verandering by God. Hy was eers kwaad en het sy stemming verander en goed geword. Terwyl Josefus en die 2de Makkabeërboek die vorm dia- of katallássein tini gebruik, gebruik Paulus die vorm katallássein tina heatō.

Wat wel waar is, is dat Paulus soos ander Griekssprekende Jode die Griekse woorde dia- of katallássein kon gebruik om God se vergewende optrede jeens die mens uit te druk.

Ons konkludeer dus dat die religieuse gebruik van dia- of katallássein binne die Griekssprekende Jodedom wel 'n parallelle verskynsel tot die gebruik by Paulus is, maar nie as die oorsprong van Paulus se gebruik 
kan geld nie. Wanneer ons die herkoms van Paulus se versoeningsteologie wil verklaar, sal ons na die twee dinge wat tot nou toe nog nie gefynkam is nie, moet kyk: die algemene gebruik in die koine en die gebruik in 2 Korintiërs 5:18-21.

\section{PROBLEEM VIER: PAULUS SE VERSOENINGSTERMINOLOGIE EN DIE ALGEMENE GEBRUIK IN DIE GRIEKS}

Wanneer die gebruik van dia- en katallássein en afleidings in die Griekse literatuur uit die Hellenistiese tyd en die tyd van die Romeinse keisers nagegaan word, kan die gebruik in die gevalle waar die woord in die betekenis 'versoen' gebruik word, soos volg saamgevat word: Hierdie 'versoen' is 'n gebeurtenis waar twee partye betrokke is en wel op so 'n manier dat die vyandige versteurde verhouding tussen hulle opgehef en deur 'n vredesverhouding vervang word. In die oorgrote meerderheid van gevalle waar dia- of katallássein gebruik is, verwys die woordgroep na 'n verandering tussen politieke teenstaanders. Die vyandelike houding tussen stadstate, leërs, generaals en regeerders word opgehef en deur ' $n$ vredesrelasie vervang. Om versoen te raak, lê baie naby aan om vrede te sluit. Daarom word katallássein of katallagás poieîn ook dikwels met eirenéuein of eirénen poieîn vervang.

Die genoemde woordgroep word dus in die Hellenistiese tydvak primêr in verband met ander diplomatieke terminologie gebruik. Benewens hierdie diplomatieke gebruik word die woordgroep ook gebruik om die verandering van vyandskap na vriendskap in die verhouding tussen individue uit te druk.

In die antieke versoeningsproses speel die ambassadeur ' $n$ belangrike rol. Die sogenaamde gesant, legatus of presbeús het die funksie om die senaat, of die polís die strategós by sy teenstanders te verteenwoordig. In talle tekste van die antieke historiograwe kan aangetoon word hoe die presbeús verteenwoordigend as gesant optree presbeúein in die plek (hupér) van diegene wat hom gestuur het om so die versoening (katallage) tot stand te bring.

Volgens 2 Korintiërs 5:18-20 is dit duidelik dat Paulus die rol van die presbeús binne die antieke versoeningsprosedure gebruik om sy rol as apostel te verduidelik. Alhoewel Paulus Jesus voor sy bekering op 'n menslike wyse beoordeel het (2 Kor 5:16), het God Paulus, wat sy vyand was, met homself versoen en aan Paulus die versoeningsaanbod (lógos tēs katallagēs) toevertrou. Paulus tree nou as gesant van God op, so asof God self deur hom roep, vra hy (presbeúein) in die plek van 
Christus dat die gemeente hulleself met God moet laat versoen ( $k a t a l$ lássesthai).

Die gedagtestruktuur, die gebruik van katallássein en presbeúein en die hupér-uitsprake in 2 Korintiërs 5:18-20 bewys myns insiens onomstootlik dat die Pauliniese versoeningsterminologie sy oorsprong in die diplomatieke terminologie van die keisertyd het.

Paulus het die terminologie gebruik omdat dit hom kon help om sy apostelskap te verduidelik. Deurdat hy die 'versoeningsgedagte' vanuit die politieke konteks na ' $n$ teologiese konteks verplaas, plaas Paulus die terminologie in ' $n$ nuwe verband. Die betekenis van die Pauliniese versoeningsgedagte moet natuurlik deur middel van ' $n$ analise van die relevante Paulus-tekste vasgestel word. Hierdie metodologiese prinsipe verander niks aan die bevinding dat die wortels van die Pauliniese versoeningsleer in die Hellenistiese diplomatetaal lê nie. Hierdie resultaat het myns insiens vernietigende konsekwensies vir 'n Bybelse teologie wat die versoeningsbegrip as tradisie-historiese 'Leitmotiv' wil gebruik. Tradisie-histories het die Pauliniese versoeningsvoorstelling net mooi niks met die Ou-Testamentiese kultiese versoeningsteologie (kpr) te make nie. Die basis vir 'n Bybelse teologie van 'Versöhnung' of 'verzoening' was en is die 'Biblia Germanica' of 'de Statenvertaling' en nie 'n histories of filologies aantoonbare kontinuiteit tussen die $\mathrm{Ou}$ Testament en Paulus nie.

\section{PROBLEEM VYF: VERSOENING EN PLAASVERVANGING BY PAULUS}

Nêrens in die bekende Griekse tekste is die dood van iemand voorwaarde vir die versoening (katallagē) nie. Paulus neem egter die profane versoeningidee konsekwent in verband met Jesus se dood oor. Versoening sonder die dood van Christus is vir Paulus ondenkbaar. Die probleem is nou: Hoe moet hierdie dood geïnterpreteer word? Paulus meld duidelik dat die dood van Christus plaasvervangend was hupèr hèmōn (vgl net Rom 5:6-11; 2 Kor 5:15-21).

Wanneer Paulus die versoeningsgebeure (katallássein) in die lig van die plaasvervangende kruisgebeure verstaan, sluit hy aan by die teologie van die Griekssprekende Joodse Christene.

Reeds voor Paulus het die Griekssprekende Joodse Christene die feit dat Jesus van Nasaret as regverdige ' $n$ onverdiende dood gesterf het en die feit dat Hy voor sy dood aan sy dissipels die gebreekte brood met die woorde 'dit is my liggaam' gegee het, in die lig van LXX Jesaja 53 
probeer verstaan. Hulle kom tot die slotsom dat die onskuldige, die regverdige, soos die paî́s sy lewe ter wille van hulle (1 Kor 11:24), oorgegee het, dat God Jesus ter wille van die gelowiges oorgelewer het; paradídonai hupér. Paulus, die sendeling onder die heidene, besef dat Jesus nie net ter wille van die gelowiges gesterwe het nie, hy het vir die goddeloses (Rom 5:6), dit is hupèr pantōn (2 Kor 5:14) gesterf. Die dood van die een bring regverdiging vir baie (Rom 5:12-21). Sy dood as regverdige maak die versoening (katallagē) moontlik.

Hierdie interpretasie word duidelik deur die onmiddellike konteks van Romeine 5:10v en 2 Korintiërs 5:18-20 gesuggereer. Die hupèruitsprake staan hier duidelik in verband met die gedagte van die universele plaasbekledingsdood (vgl 2 Kor $5: 14 \mathrm{v}$ en 21 en Rom 5:6-8; 12-21).

Daar is heelwat ooreenkomste tussen die Griekse vertaling van Jesaja 52:13-53:12 en die onmiddellike kontekste van 2 Korintiërs 5:18-20 en Romeine $5: 10 \mathrm{v}$. Die gedagte van die plaasvervangende dood hupèr pantōn/pollōn van LXX Jesaja 53:12 word in 2 Korintiërs 5:14 oorgeneem. Die kneg van Jesaja 53 en Christus word as die regverdige beskou (Rom 5:17-19; 2 Kor 5:21; LXX Jes 53:11). Beide Christus en die kneg word veroordeel (Rom 5:16; 2 Kor 5:21; LXX Jes 53:8) en uit tekste van die vroeë Jodedom (Sophia Salomonos 5:1 vv; 1 Henog 46:44v) word duidelik dat die oordeel oor die kneg van Jesaja 53 soos die oordeel oor Christus (Rom 8:3v; 2 Kor 5:21) as eskatologiese gebeurtenis verstaan is. Soos die dood van die kneg (LXX Jes 53:10), is ook die dood van Christus dit wat die sonde wegneem (2 Kor 5:19).

Dit is opvallend dat die LXX teks Jesaja 52:13-53:12 duidelik vermeld dat die kneg (paîs) die volk vanuit die straf op hulle sonde red (vgl LXX Jes 53:4v 12), maar dat daar geen sprake daarvan is dat die paîs as 'soenoffer' oorgegee word nie. Die $\bar{a} s \bar{a} a m$ van die Hebreeuse teks word in die LXX-weergawe van Jesaja 53:10 deur kai döte peri hamartías he psúche humōn hópsetai spérma makróbion vervang. Daar is geen rede om te beweer dat die LXX die dood van die kneg as 'n 'soenoffer' verstaan het nie.

Die gevolgtrekking tot hierdie gedeelte is dat Paulus die katallagegedagte, wat hy oorgeneem het om sy apostolaat as diens van die versoening te beskryf, in die lig van die kruis van Christus verduidelik. Paulus sien die saak so, dat die dood van Christus, omdat dit die mens se sonde wegneem, die versoening moontlik maak. Die dood van Christus bevry die mens vanuit die doodsgevolge van die sonde, omdat die regverdige Christus in die plek van die mens geoordeel is. 
Die kruisiging word, na aanleiding van die oordeel oor die paîs van LXX Jesaja 53, as God se eskatologiese oordeel oor die sonde verstaan (vgl Rom 8:3). God maak Christus tot sondaar (2 Kor 5:21) en vernietig Hom in plaas van die mens, sodat die mens wat in Christus nuutgeskape is (2 Kor 5:17) geregverdig kan wees (2 Kor 5:21)*. Die plek waar God genadig die mens vanuit die doodsgevolge van sonde verlos, is nie meer die tempel nie. Deur die dood aan die kruis is Jesus openlik opgerig as die plek waar God genadig teenwoordig is (hilastērion - Rom 3:25).

* Die kundige leser sou opgemerk het dat die dood $t w$ hier nie as kultiese offerdood verstaan is nie, maar as plaasbekledingsdood met die oog op die eindoordeel (word vervolg).

\section{Literatuurverwysings}

FRYER, NSL 1985. 'n Adekwate versoeningsterminologie? NGTT 25, 18-32. 